Supplement of

\title{
Low modeled ozone production suggests underestimation of precursor emissions (especially $\mathrm{NO}_{x}$ ) in Europe
}

Emmanouil Oikonomakis et al.

Correspondence to: Sebnem Aksoyoglu (sebnem.aksoyoglu@psi.ch)

The copyright of individual parts of the supplement might differ from the CC BY 4.0 License. 
Table S1. Summary of WRF parameterizations (http://wrf-model.org).

\begin{tabular}{ll}
\hline Parameter & Option \\
\hline Microphysics & WRF Single-Moment 5-class (WSM5). \\
\hline Longwave and Shortwave Radiation & $\begin{array}{l}\text { Rapid Radiative Transfer Model for general circulation } \\
\text { models (RRTMG). }\end{array}$ \\
\hline Surface Layer & $\begin{array}{l}\text { Revised version of the fifth generation Pennsylvania State } \\
\text { University-National Center for Atmospheric Research } \\
\text { Mesoscale Model (MM5) parameterization. }\end{array}$ \\
\hline Land Surface & Noah land surface model (LSM). \\
\hline PBL & Yonsei University non-local closure scheme (YSU). \\
\hline Cumulus Parameterization & Kain-Fritsch. \\
\hline Dynamics \& FDDA & Recommendations of WRF user's guide. \\
\hline
\end{tabular}

5 Table S2. Description of SNAP source categories in TNO-MACC-III (as in Kuenen et al., 2014).

\begin{tabular}{ll}
\hline SNAP & SNAP sector description \\
\hline 1 & Energy industries \\
\hline 2 & Non-industrial combustion \\
\hline $34(3+4)$ & Industry (combustion and processes) \\
\hline 5 & Extraction and distribution of fossil fuels \\
\hline 6 & Product use \\
\hline 7 & Road transport \\
\hline 8 & Non-road transport and other mobile sources \\
\hline 9 & Waste treatment \\
\hline 10 & Agriculture \\
\hline
\end{tabular}


Table S3. Overview of ozonesonde stations.

\begin{tabular}{lccccc}
\hline Station & Longitude (deg) & Latitude (deg) & Elevation (m) & Daily Records & UTC time \\
\hline Valentia & $10.25 \mathrm{~W}$ & $51.93 \mathrm{~N}$ & 14 & 7 & $11: 00-12: 00$ \\
\hline Barajas & $3.58 \mathrm{~W}$ & $40.47 \mathrm{~N}$ & 631 & 12 & $10: 00-11: 00$ \\
\hline Legionowo & $20.97 \mathrm{E}$ & $52.40 \mathrm{~N}$ & 96 & 9 & $11: 00-12: 00$ \\
\hline Hohenpeissenberg & $11.00 \mathrm{E}$ & $47.80 \mathrm{~N}$ & 976 & 25 & $04: 00-06: 00$ \\
\hline Payerne & $6.57 \mathrm{E}$ & $46.49 \mathrm{~N}$ & 491 & 36 & $11: 00-12: 00$ \\
\hline Uccle & $4.35 \mathrm{E}$ & $50.80 \mathrm{~N}$ & 100 & 40 & $11: 00-12: 00$ \\
\hline
\end{tabular}

5 Table S4. Overview of stations used for ozone-temperature correlation analysis in Fig. 7.

\begin{tabular}{lccc}
\hline Station & Longitude (deg) & Latitude (deg) & Elevation (m) \\
\hline Payerne & $6.95 \mathrm{E}$ & $46.81 \mathrm{~N}$ & 489 \\
\hline Kucharovice & $16.09 \mathrm{E}$ & $48.88 \mathrm{~N}$ & 334 \\
\hline Kocelovice & $13.84 \mathrm{E}$ & $49.47 \mathrm{~N}$ & 519 \\
\hline Kramolin-Kosetice & $15.08 \mathrm{E}$ & $49.57 \mathrm{~N}$ & 535 \\
\hline Meiningen & $10.38 \mathrm{E}$ & $50.56 \mathrm{~N}$ & 450 \\
\hline Nice & $7.20 \mathrm{E}$ & $43.65 \mathrm{~N}$ & 2 \\
\hline Cabauw & $4.93 \mathrm{E}$ & $51.97 \mathrm{~N}$ & -1 \\
\hline Leba & $17.53 \mathrm{E}$ & $54.75 \mathrm{~N}$ & 4 \\
\hline
\end{tabular}



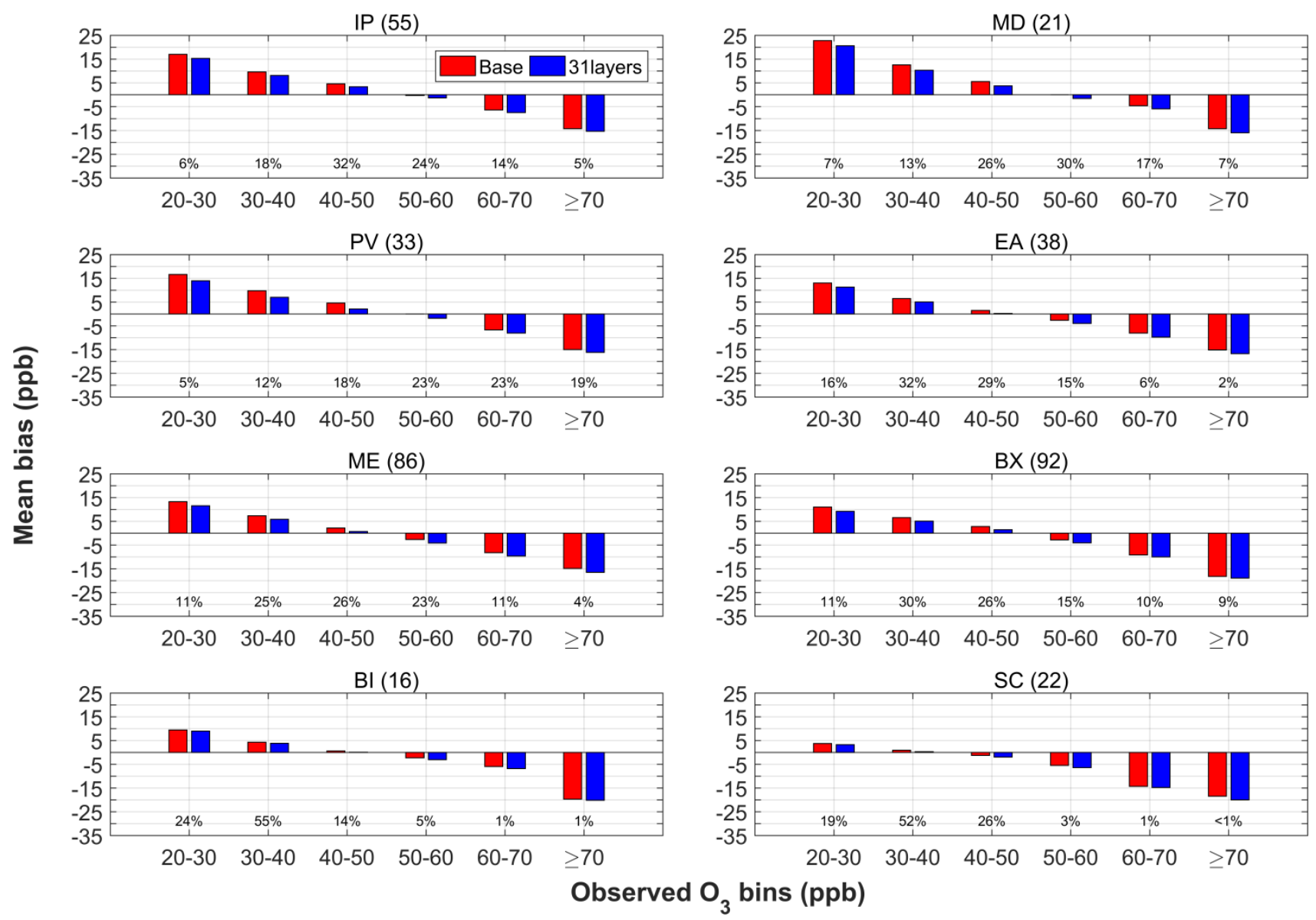

Figure S1. Effect of increasing vertical resolution (31 layers up to $100 \mathrm{hPa}$ instead of 14 layers up to $460 \mathrm{hPa}$ ) on the mean afternoon (12:00-18:00 UTC) bias for surface $\mathrm{O}_{3}$ mixing ratios in 8 European regions in June 2010. Percentage values below the bars indicate the fraction of the values assigned to each bin for each region. The number of stations available for each region is reported in parentheses at the top of each panel. A definition of the regions is given in Fig. 1. 
(a) Isoprene

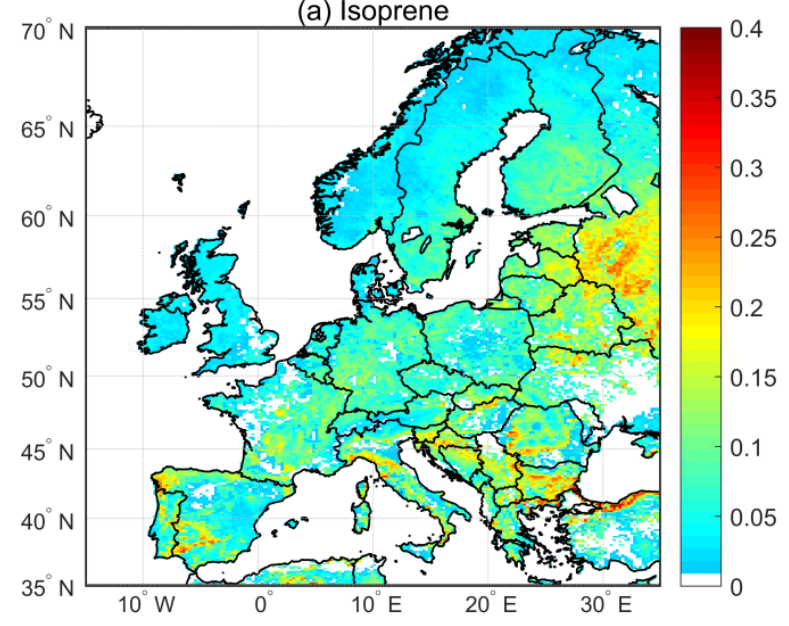

(c) Sesquiterpenes

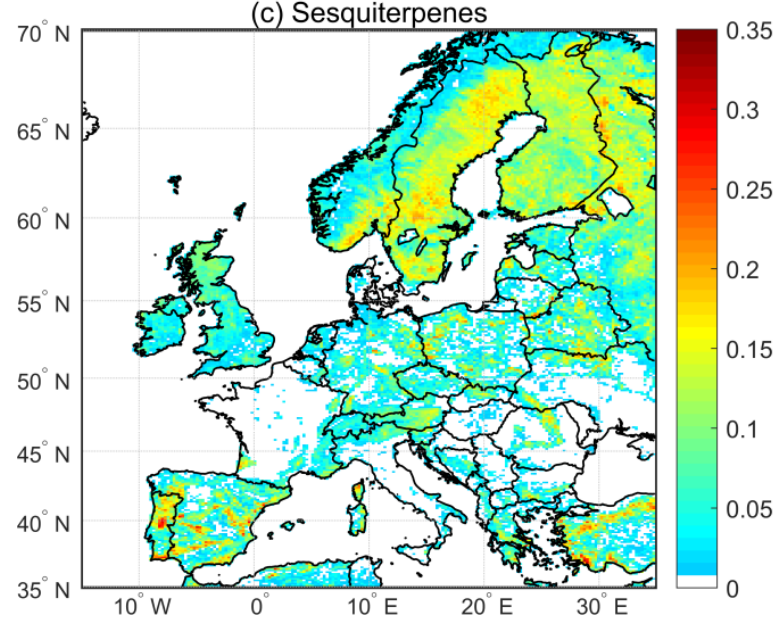

(b) Monoterpenes

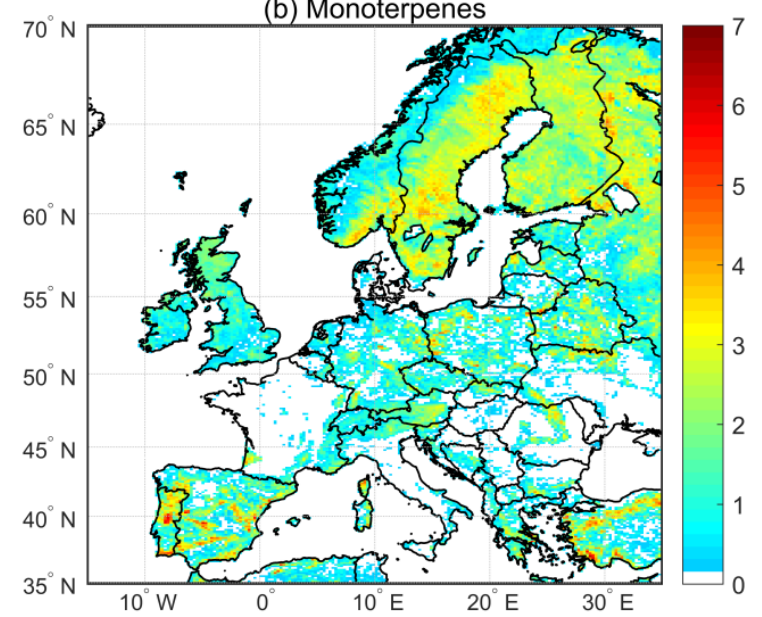

(d) soil NO

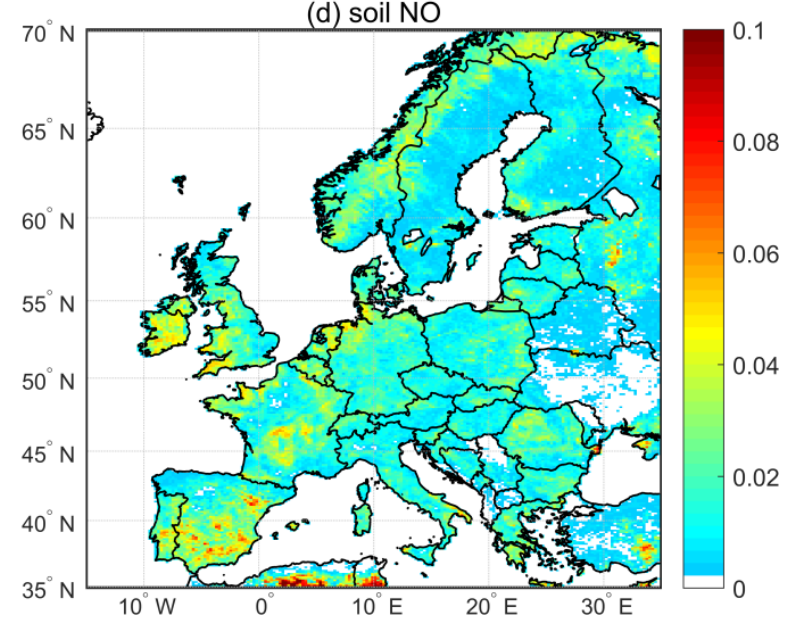

Figure S2. Spatial distributions of total (a) isoprene, (b) monoterpene, (c) sesquiterpene and (d) soil NO emissions (t km ${ }^{-2}$ ) integrated over the summer (JJA) of 2010 in Europe. 

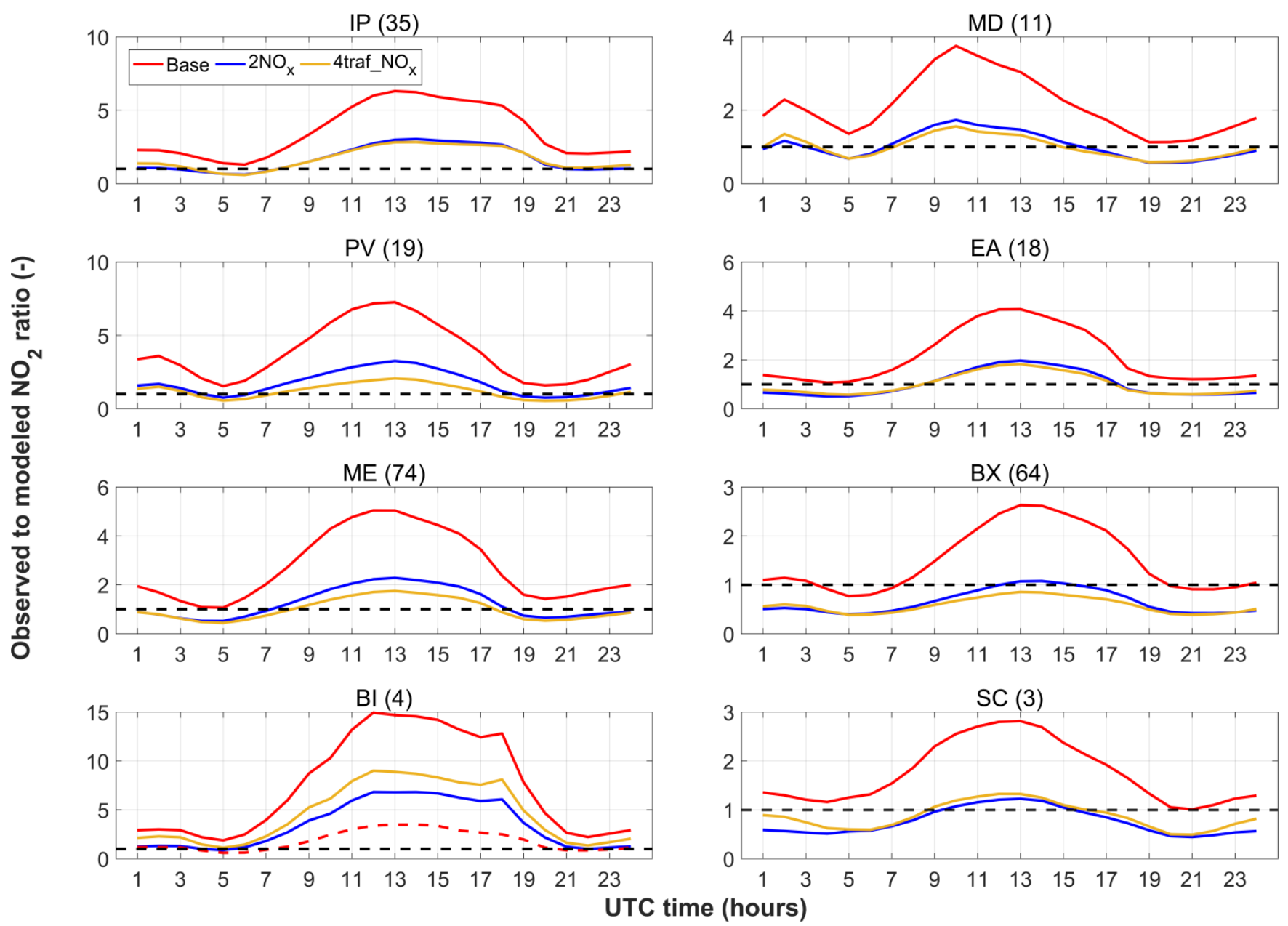

Figure S3. Diurnal profile of the ratio of observed to modeled surface $\mathrm{NO}_{2}$ mixing ratios in 8 European regions in summer 2010. The number of stations available for each region is reported in parentheses at the top of each panel. The dashed black line is the ratio of 1 . Red line shows the base case, blue line shows the scenario with doubled $\mathrm{NO}_{\mathrm{x}}$ emissions $\left(2 \mathrm{NO}_{\mathrm{x}}\right)$ and

5 yellow line shows the scenario with quadrupled traffic $\mathrm{NO}_{\mathrm{x}}$ emissions (4traf_NO $\mathrm{NO}_{\mathrm{x}}$ ). The dashed red line shows the base case averaged over 3 stations instead of 4, excluding the station Fort William in northern UK (GB0885A; 5.10W, 56.82N) which was considered to be an outlier. A definition of the regions is given in Fig. 1. 


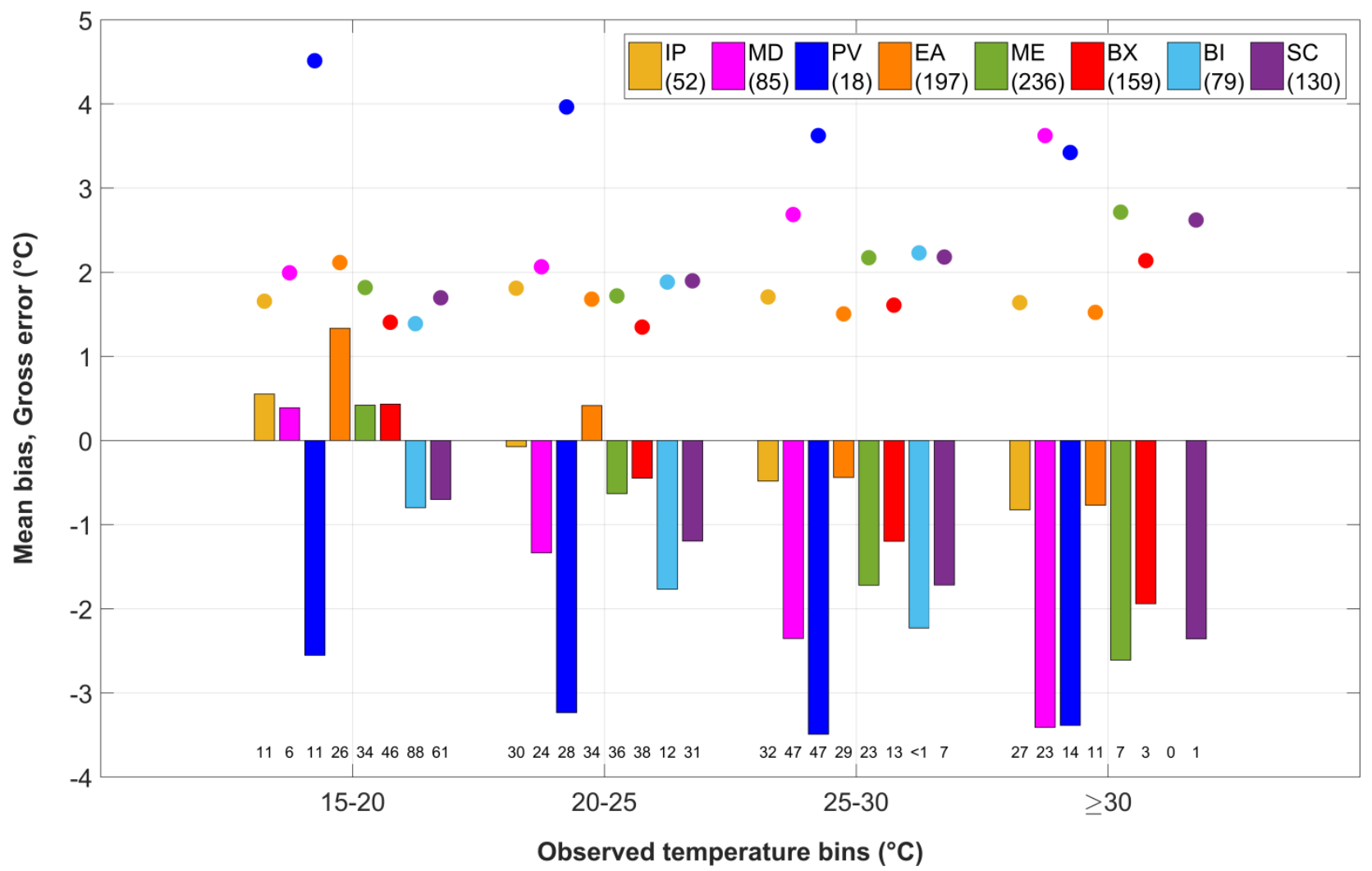

Figure S4. Temperature $(2 \mathrm{~m})$ mean bias (bars) and gross error (dots) for observed afternoon (12:00-18:00 UTC) temperature bins in 8 European regions in summer 2010. Values below the bars indicate the fraction (\%) of the values assigned to each bin for each region. The number of stations available for each region is reported in parentheses in the 5 legend. A definition of the regions is given in Fig. 1. 


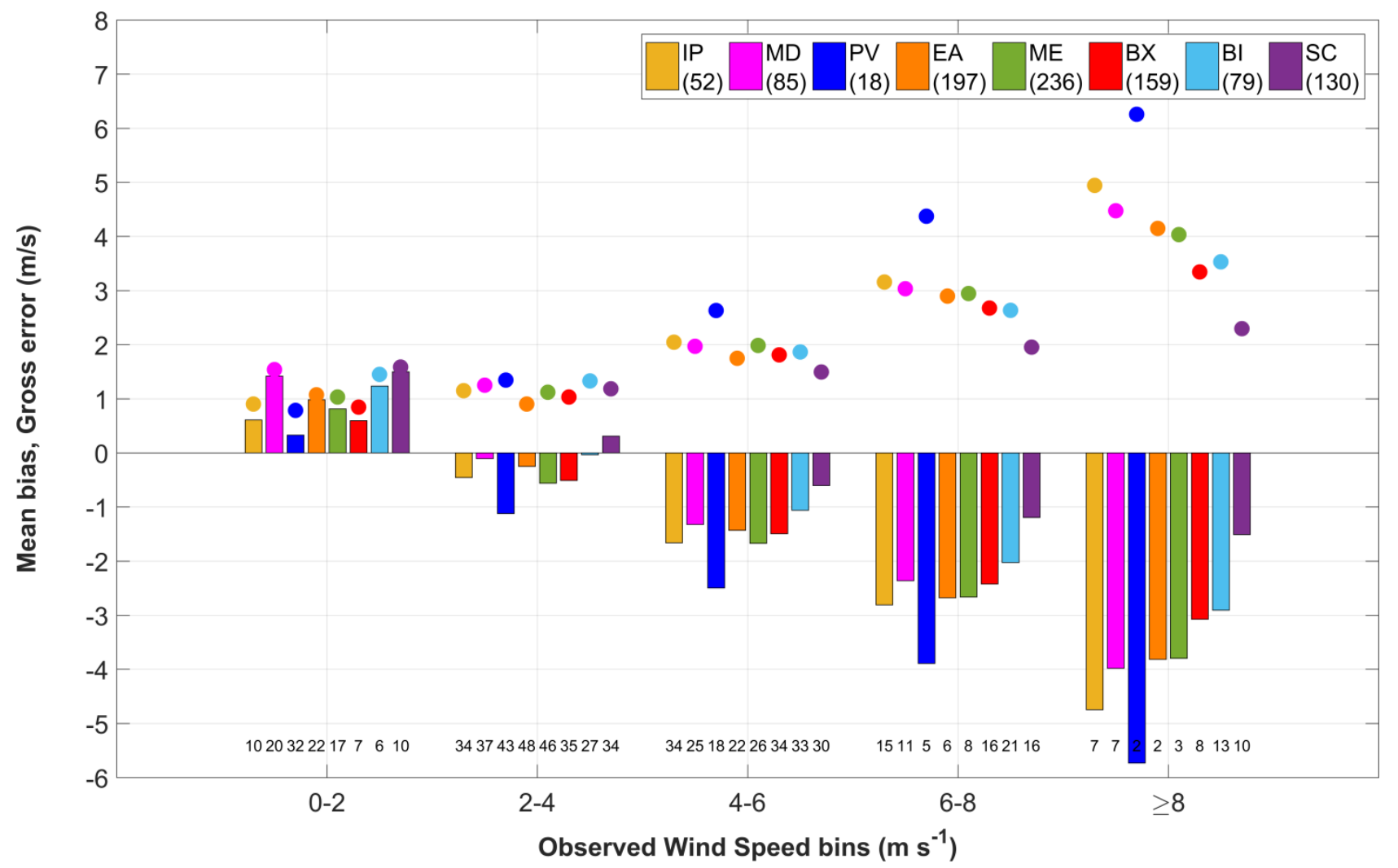

Figure S5. Wind speed $(10 \mathrm{~m})$ mean bias (bars) and gross error (dots) for observed afternoon (12:00-18:00 UTC) wind speed bins in 8 European regions in summer 2010. Values below the bars indicate the fraction (\%) of the values assigned to each bin for each region. The number of stations available for each region is reported in parentheses in the legend. A 5 definition of the regions is given in Fig. 1. 


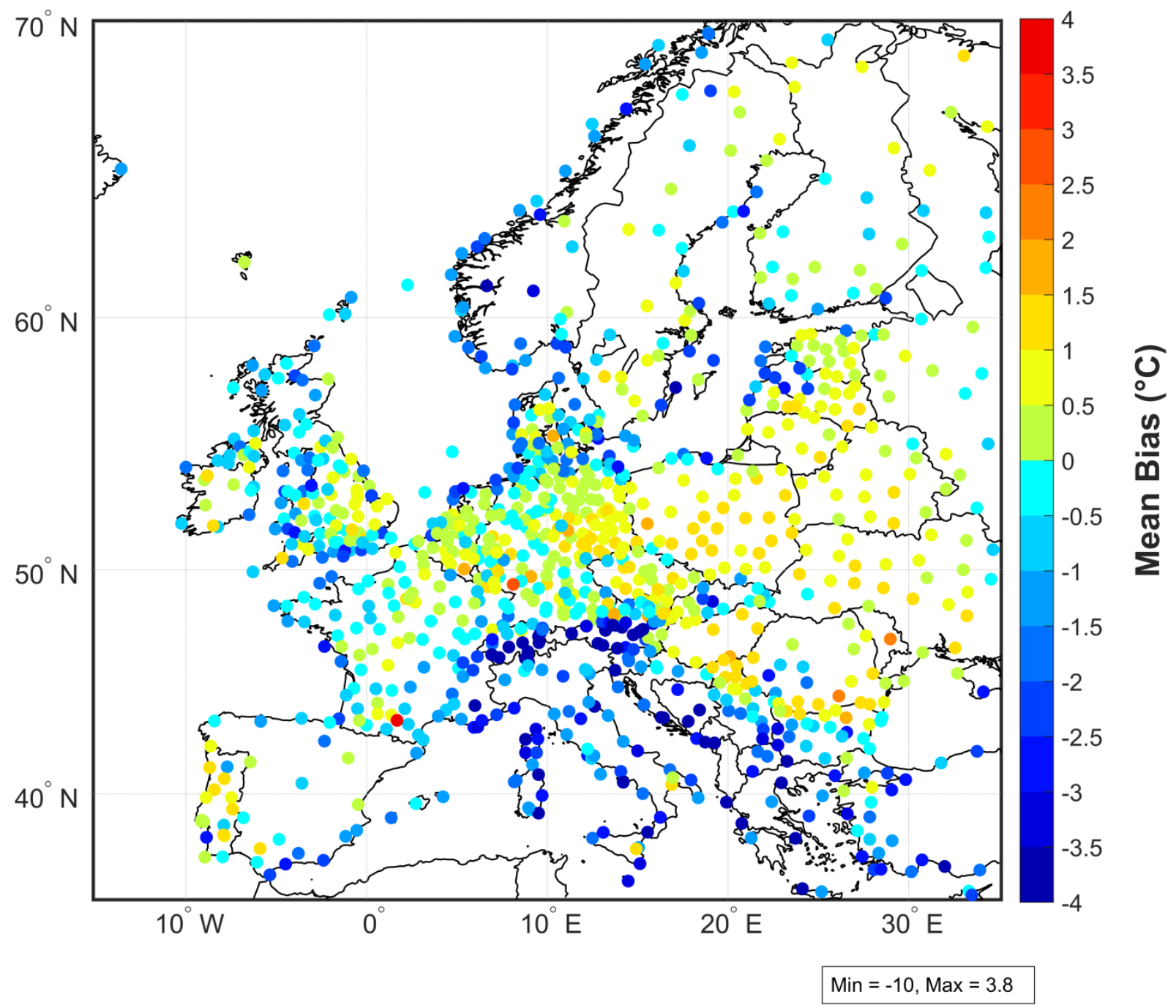

Figure S6. Temperature (2 m) afternoon (12:00-18:00 UTC) mean bias for each station in Europe for the summer of 2010. There are 18 stations outside the color scale. 


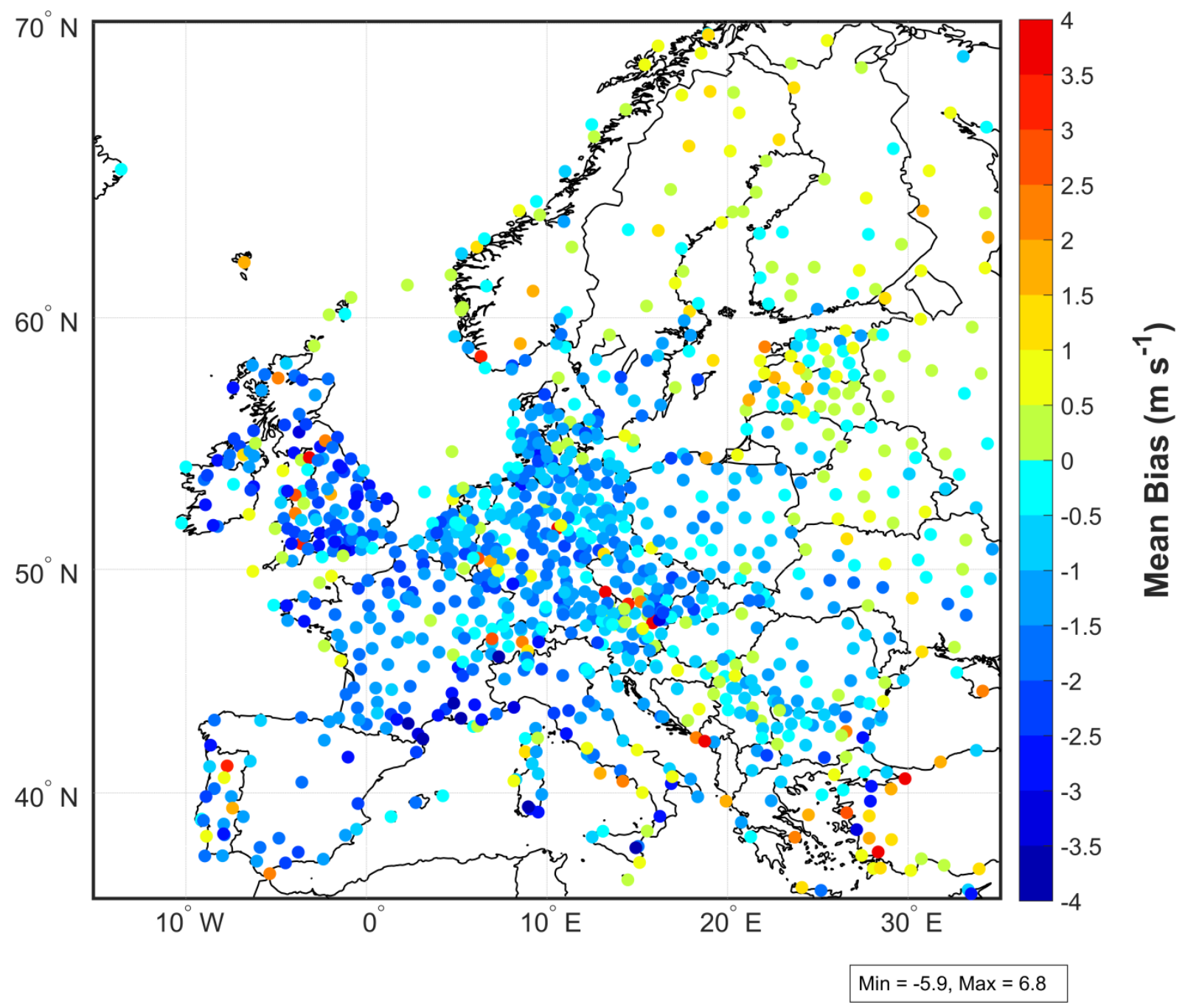

Figure S7. Wind speed (10 m) afternoon (12:00-18:00 UTC) mean bias for each station in Europe for the summer of 2010. There are 8 stations outside the color scale. 


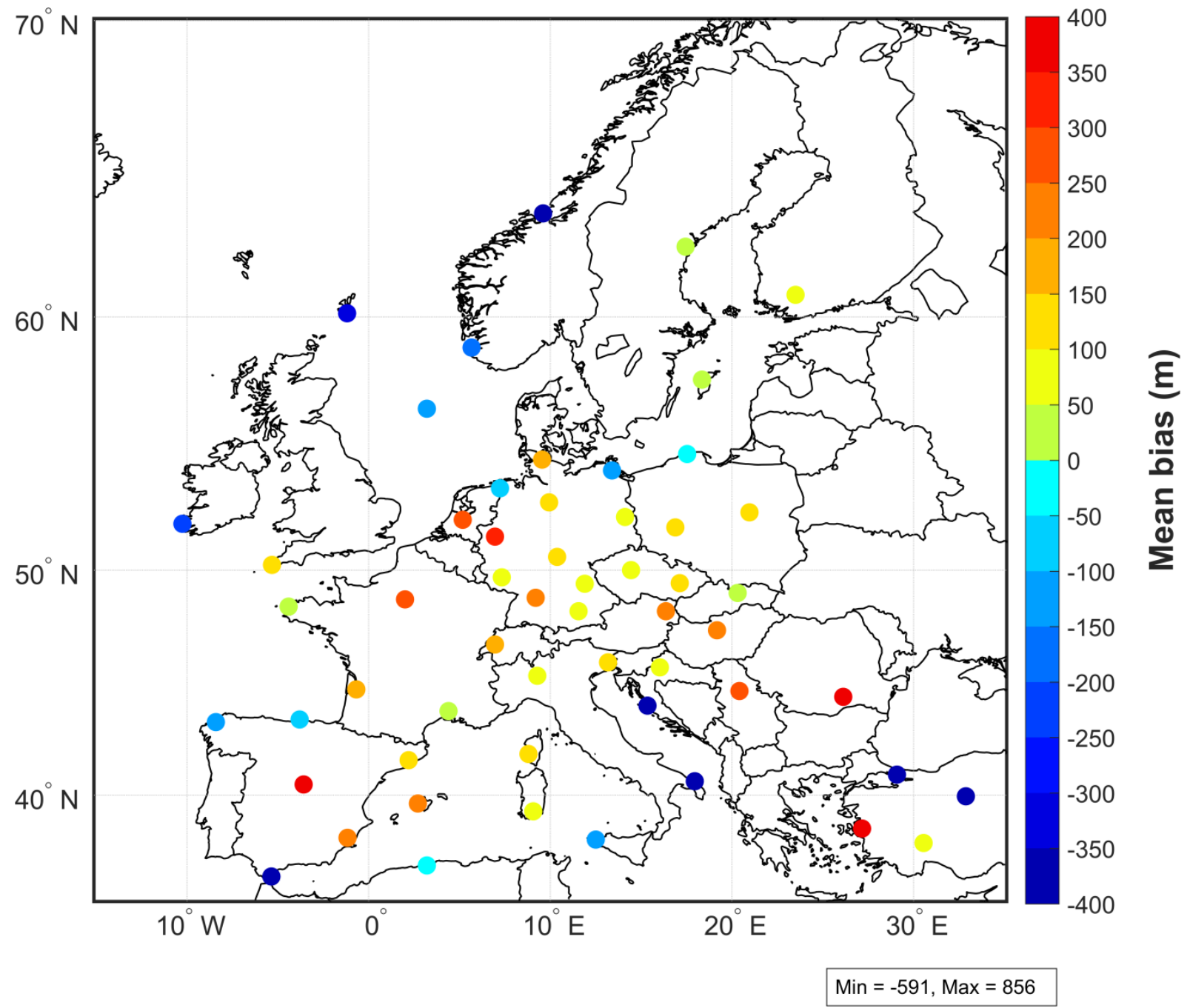

Figure S8. PBLH mean bias at 12 UTC for each station in Europe for the summer of 2010. There are 5 stations outside the color scale. 

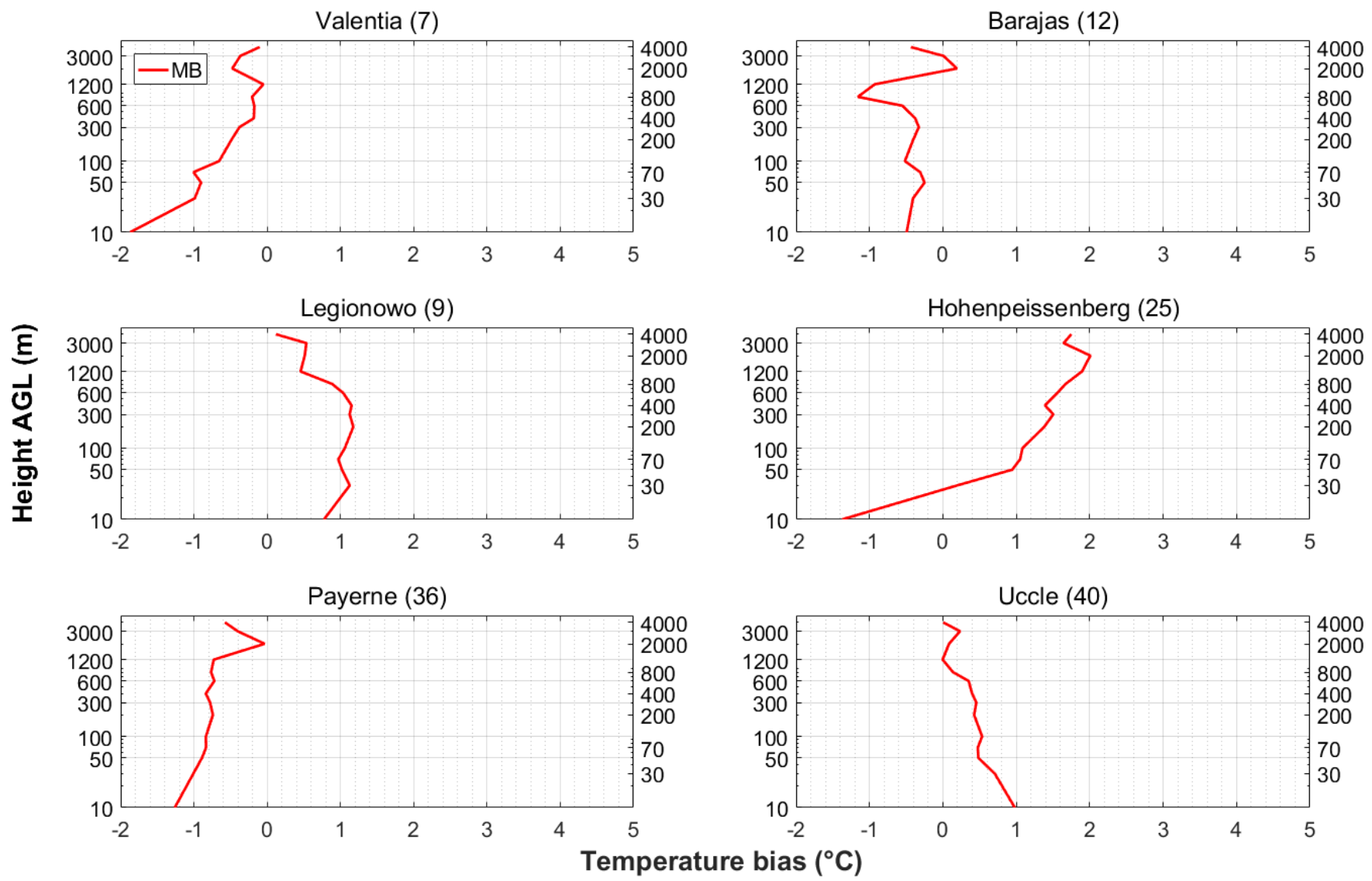

Figure S9. Vertical profiles of temperature mean bias for 6 stations for the summer of 2010. The number of ozonesondes available for each station is reported in parentheses at the top of each panel. Heights of 14 model layers are shown on both y5 axes which are in logarithmic scale. 

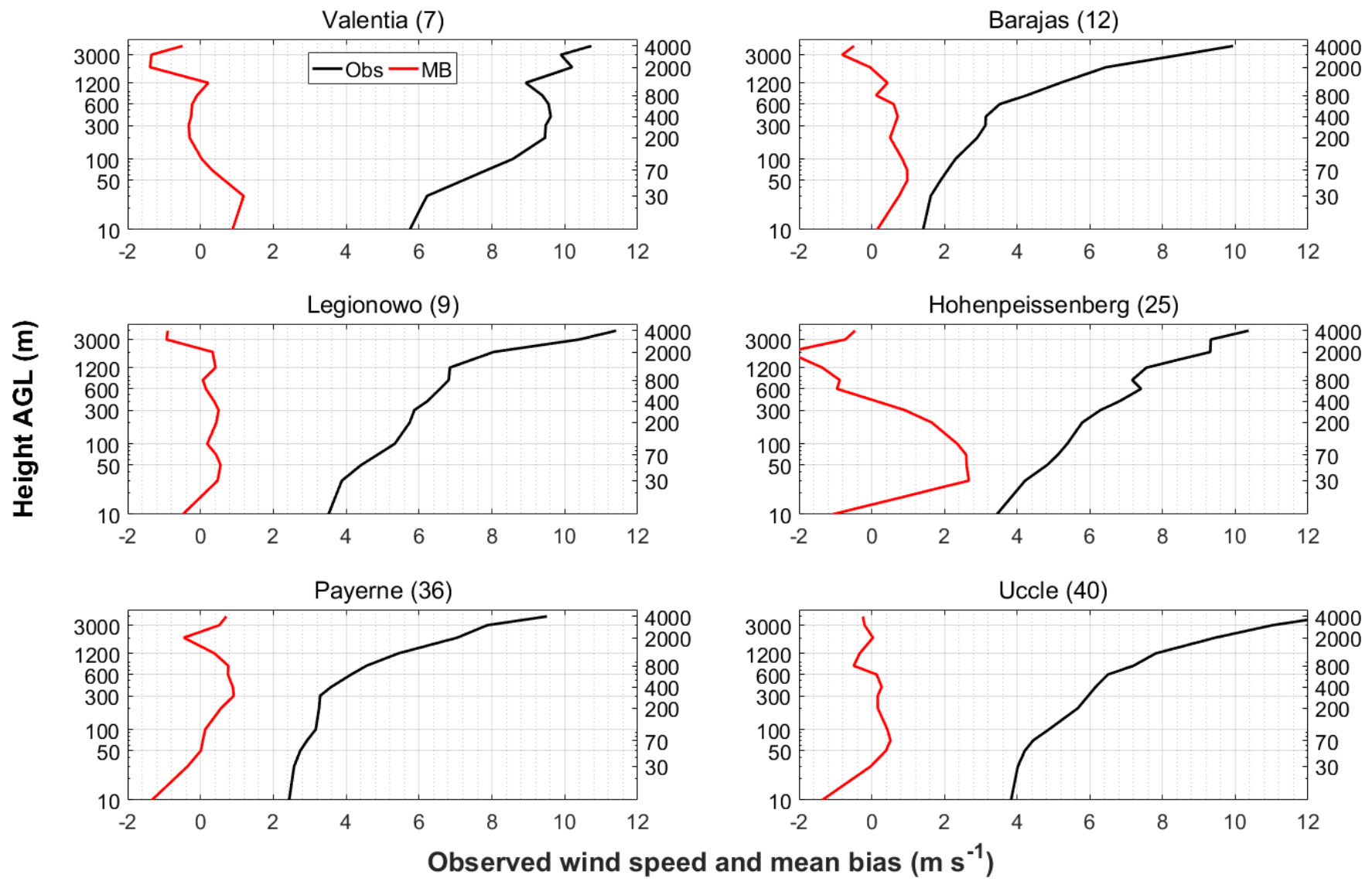

Figure S10. Vertical profiles of observed wind speed and mean bias for 6 stations for the summer of 2010. The number of ozonesondes available for each station is reported in parentheses at the top of each panel. Heights of 14 model layers are 5 shown on both y-axes which are in logarithmic scale. 

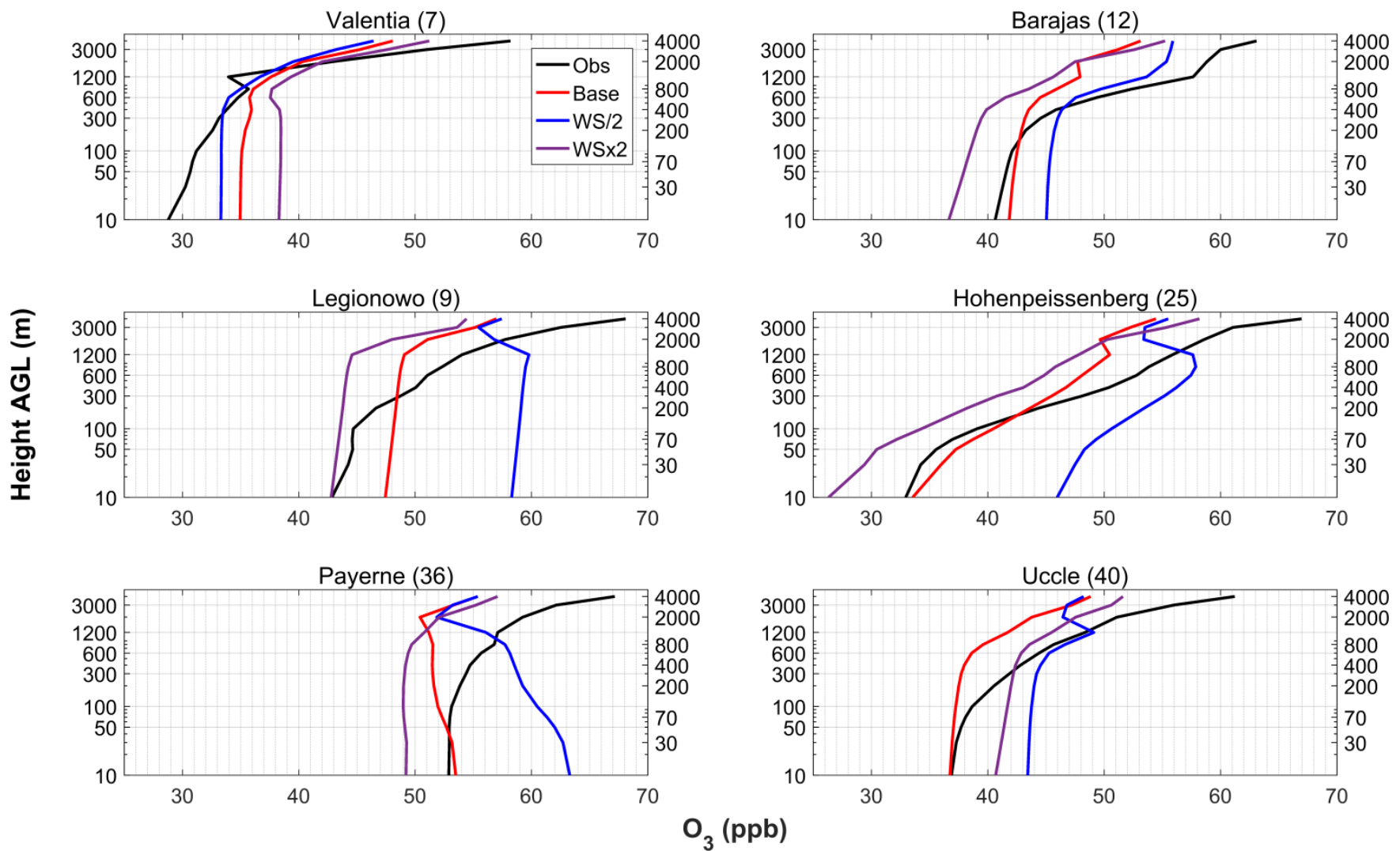

Figure S11. Observed and modeled $\mathrm{O}_{3}$ mixing ratio vertical profiles for 6 stations for the summer of 2010. The number of ozonesondes available for each station is reported in parentheses at the top of each panel. Heights of 14 model layers are 5 shown on both y-axes which are in logarithmic scale. 

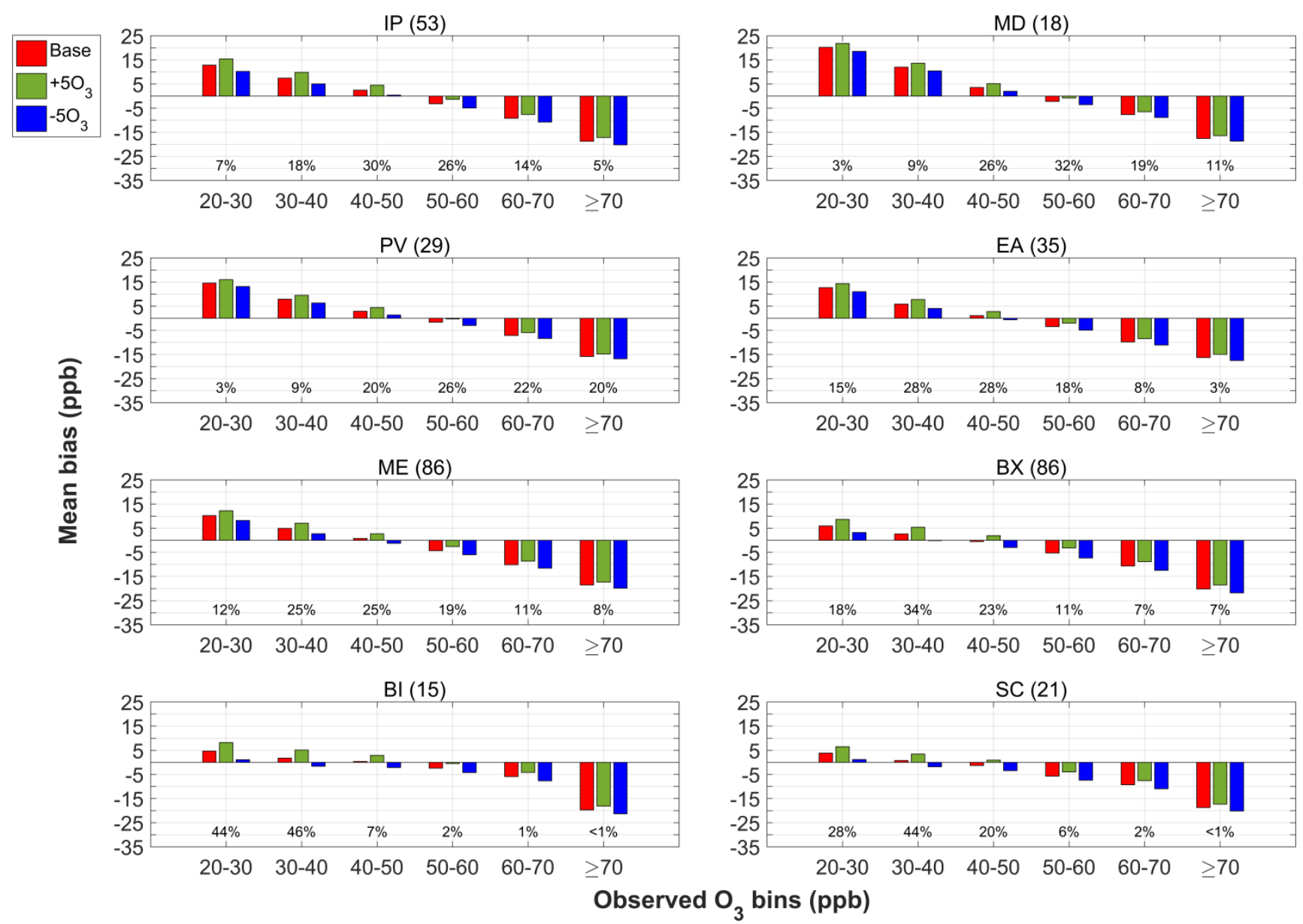

Figure S12. Mean bias of the afternoon (12:00-18:00 UTC) surface $\mathrm{O}_{3}$ mixing ratio for each bin of observed surface $\mathrm{O}_{3}$ mixing ratios for various $\mathrm{O}_{3}$ ICBC scenarios in 8 European regions in summer 2010. Percentage values below the bars indicate the fraction of the values assigned to each bin for each region. The number of stations available for each region is

5 reported in parentheses at the top of each panel. A definition of the regions is given in Fig. 1. 